ORIGINAL ARTICLE

\title{
Bronchiectasis in Pediatric HIV Infection: An Indian
}

\section{Perspective}

\author{
GN Sanjeeva ${ }^{1}$, Kani Varshneya ${ }^{2}$, HB Pavithra ${ }^{3}$, RL Ramesh ${ }^{4}$, Thomas Semple ${ }^{5}$, Catherine M Owens ${ }^{6}$, Samatha Sonnappa ${ }^{7}$
}

\begin{abstract}
Background: Children with vertically acquired HIV-infection (CLHIV) surviving into adulthood are susceptible to sequelae such as chronic lung disease (CLD) including bronchiectasis. Our objective was to characterize bronchiectasis radiologically and functionally, estimate prevalence, and determine risk factors in Indian CLHIV.

Meterials and methods: In this prospective cross-sectional study, CLHIV aged 5-18 years were categorized into either high-resolution computed tomography (HRCT) confirmed bronchiectasis or control groups without clinical evidence of CLD. Clinical and radiological evaluations, chart review, spirometry, and 6-minute walk test (6MWT) were performed. Baseline characteristics of both groups were compared using Mann-Whitney $\mathrm{U}$ or Chi-square, or $t$ tests. Multivariable logistic regression was used to determine factors independently associated with bronchiectasis.

Findings: Four hundred and eleven CLHIV with median (IQR) age 12 years (9.5-14.5) were screened. Thirty-nine (10.6\%) children had bronchiectasis and 160 with no CLD were controls. Mean \pm SD of zFEV $1(-2.61 \pm 0.9)$ and zFVC $(-2.0 \pm 0.8)$ in the bronchiectasis group was significantly lower than that of control group ( $\left(\mathrm{FEVV}_{1}=-0.37 \pm 0.87 ; \mathrm{zFVC}=-0.55 \pm 0.88\right)$. During $6 \mathrm{MWT}, 41 \%$ in the bronchiectasis group desaturated $(\mathrm{Chi}-\mathrm{square}=$ $6.19 ; p=0.01$ ) as compared to $20 \%$ in control group and $76 \%$ covered $<3$ rd centile distance (Chi-square $=3.95 ; p=0.047$ ) as compared to $57 \%$ in control group. Age $>5$ years (OR-3.39; $95 \% \mathrm{Cl}[1.30,8.87])$ at HIV-diagnosis and recurrent sinopulmonary infections (OR-2.37; 95\% $\mathrm{Cl}$ [1.07, 5.24]) were found to be independent risk factors for the development of bronchiectasis.

Interpretation: Bronchiectasis was seen in $9.5 \%$ of our cohort of CLHIV causing significantly abnormal pulmonary function. Late HIV diagnosis (age $>5$ years) and recurrent sinopulmonary infections were independent risk factors for developing bronchiectasis.

Keywords: Bronchiectasis, FEV 1 , HIV-infected children, Risk factors.

Pediatric Infectious Disease (2019): 10.5005/jp-journals-10081-1204
\end{abstract}

\section{INTRODUCTION}

Many children with vertically acquired human immunodeficiency virus (CLHIV) infection are surviving into adulthood as the pediatric HIV national program in India enters into its second decade. The majority of these individuals have a heavy burden of chronic sequelae, such as growth failure, pulmonary disease, and drug related toxicities. ${ }^{1}$ Despite scaling up of services to prevent mother to child HIV transmission, undiagnosed older children with HIV infection still account for majority of new enrolments in India. ${ }^{2}$

The prevalence of recurrent lower respiratory tract infections (LRTI) and tuberculosis (TB) in HIV-infected children is high, placing these children at risk of developing chronic lung disease (CLD) including bronchiectasis. ${ }^{3,4}$ Consequently, a new heterogeneous group of HIV-infected children with CLD include antiretroviral therapy (ART) exposed adolescent children and newly diagnosed older children representing a previously under recognized but emerging facet of the HIV epidemic in India.

There are limited studies of bronchiectasis in children particularly in those with HIV infection. ${ }^{5}$ Bronchiectasis is infrequently diagnosed because of a low index of suspicion and inaccessibility of the relatively expensive gold-standard diagnostic high-resolution computed tomography (HRCT) in developing countries. The objective of our study was to determine the prevalence of bronchiectasis, characterize bronchiectasis radiologically and functionally, and determine associated risk factors in Indian CLHIV.

\section{Materials and Methods}

This prospective cross-sectional case control study was conducted at the Pediatric Center of Excellence (PCOE) for HIV care, Indira \begin{tabular}{l}
\hline \hline${ }^{1,3}$ Pediatric Centre of Excellence, Indira Gandhi Institute of Child \\
Health, Bengaluru, Karnataka, India \\
${ }^{2}$ Imperial College London, Kensington, London, UK \\
${ }^{4}$ Indira Gandhi Institute of Child Health, DR College Post, Bengaluru, \\
Karnataka, India \\
${ }^{5}$ Radiology Department, The Royal Brompton and Great Ormond \\
Street Hospitals, London, UK \\
${ }^{6}$ Cardiorespiratory Unit, Great Ormond Street Hospital, London, UK \\
${ }^{7}$ Royal Brompton Hospital and Harefield Hospital, Chelsea, West \\
London, UK \\
Corresponding Author: GN Sanjeeva, Pediatric Center of Excellence, \\
Indira Gandhi Institute of Child Health, Bengaluru, Karnataka, India, \\
Phone: +919945657034, e-mail: sanju.gn26@gmail.com \\
How to cite this article: Sanjeeva GN, Varshneya K, Pavithra HB, et al. \\
Bronchiectasis in Pediatric HIV Infection: An Indian Perspective. Pediatr \\
Inf Dis $2019 ; 1(2): 45-51$. \\
Source of support: Nil \\
Conflict of interest: None
\end{tabular}

Gandhi Institute of Child Health (IGICH), Bengaluru, India, from January 2014 to December 2014. Informed written consent from the parents or legal guardians of the children and verbal assent from each child was obtained. The Institutional Ethical Committee approved the study.

\section{Study Participants}

All CLHIV between 5 years and 18 years of age attending the ART clinic were considered for enrollment and assessed for CLD.

(-) The Author(s). 2019 Open Access This article is distributed under the terms of the Creative Commons Attribution 4.0International License (https://creativecommons. org/licenses/by-nc/4.0/), which permits unrestricted use, distribution, and non-commercial reproduction in any medium, provided you give appropriate credit to the original author(s) and the source, provide a link to the Creative Commons license, and indicate if changes were made. The Creative Commons Public Domain Dedication waiver (http://creativecommons.org/publicdomain/zero/1.0/) applies to the data made available in this article, unless otherwise stated. 
Assessments included detailed history, anthropometry, clinical examination, and World Health Organization (WHO) clinical staging of HIV disease, which were recorded in prestructured proformas. Height, weight, and BMI were expressed as gender-specific $z$-scores based on Indian growth charts. ${ }^{6}$ Charts were reviewed for age at diagnosis, mode of transmission, baseline nutritional, clinical and immunological status, previous history of $\mathrm{TB}$, and preceding recurrent sinopulmonary infections. All children were screened for TB as per the revised national TB control program. ${ }^{7}$ Children with active TB disease were referred for appropriate treatment and were excluded from the study.

A child was considered to have CLD if two or more of the following features were present: ${ }^{8}$ (i) chronic cough (present most days for 3 months of the year in the past 2 years), (ii) recurrent sinopulmonary infections ( $\geq 2$ episodes of serious sinus or lower respiratory infections in a single year or $\geq 3$ episodes ever), (iii) moderate to severe limitation in physical activity caused by breathlessness (New York Heart Association class 2-4), (iv) an existing diagnosis and/or clinical signs of cor pulmonale such as finger clubbing, raised jugular venous pressure, and (v) hypoxia $\left(\mathrm{O}_{2}\right.$ saturations $<92 \%$ at rest) or desaturation $(\geq 5 \%)$ on exercise.

\section{Bronchiectasis Group}

All children with suspected CLD underwent non-contrast HRCT in the same CT scanner (AQUILLION-16, TOSHIBA, Japan) and were reported by two independent radiologists using a standardized scoring system, ${ }^{9}$ with discrepancies resolved by consensus. Children with HRCT confirmed bronchiectasis were included in the study as bronchiectasis group. As per the Fleischer society glossary of terms, bronchiectasis was defined as bronchial dilation with an internal lumen diameter greater than that of the accompanying pulmonary artery or a lack of bronchial tapering. ${ }^{10}$ Bronchiectasis was further classified into focal disease when confined to one lobe, multifocal disease between two and four lobes, and diffuse disease when in more than four lobes. ${ }^{11}$

\section{Control Group}

The control group included children without clinical evidence of CLD and the following exclusion criteria: children who (i) were currently taking anti-TB treatment, (ii) reported acute respiratory symptoms ( $\leq 1$ week of any one or more of fever, cough, purulent sputum, and pleuritic chest pain), (iii) required emergency hospitalization, (iv) had a history of documented recurrent wheeze, and (v) had abnormal spirometry or were unable to reliably perform spirometry.

\section{Pulmonary Function Tests}

Spirometry assessments were performed according to ATS/ERS standards adapted for children using the portable Easy-on-PC spirometer (ndd, Switzerland). All assessments were undertaken with the child seated and nose clip in situ. Successful spirometry was defined as those with at least two technically acceptable forced expiratory maneuvers according to ATS/ERS acceptability and repeatability criteria adapted for children. ${ }^{12}$ All spirometry data were subjected to independent quality control using the same over-read method. ${ }^{12}$ Forced vital capacity (FVC), forced expiratory volume in 1 second $\left(\mathrm{FEV}_{1}\right)$, and $\mathrm{FEV}_{1} / \mathrm{FVC}$ are reported as $z$-scores. All data were adjusted for age, sex, and height and expressed using recently derived "GLI-2012 Indian" spirometry coefficients. 13,14

All children performed the 6-minute walk test (6MWT) as per the ATS guidelines to determine exercise tolerance. ${ }^{15}$ The distance covered during the 6MWT by children was plotted against the age and sex-specific normograms for healthy children. ${ }^{16}$

\section{Statistical Methods}

Data are presented as median [interquartile ranges (IQR)], mean [standard deviation (SD)], and proportions. Baseline characteristics of the bronchiectasis and control groups were compared using Mann-Whitney $U$, Chi-square, or $t$ tests, as appropriate. Multivariable logistic regression was used to determine factors independently associated with bronchiectasis. All variables with $p$ value $\leq 0.05$ at univariate analysis such as age of HIV diagnosis, baseline height for age and immunological status, and preceding recurrent sinopulmonary infections were included in the model. A two-tailed $p$ value $<0.05$ was considered statistically significant. All analyses were performed using SPSS software for Windows (version 16.0; SPSS, Inc., Chicago, Illinois). Graphs were created with GraphPad Prism (version 5: GraphPad Software, San Diego, California).

\section{Results}

Four hundred and eleven children were screened and 42 were excluded with evidence of active TB, respiratory tract infections, or horizontal transmission of HIV. Of the remaining 369 children, 160 (43.4\%) had no clinical evidence of CLD and formed the control group. One hundred and thirty-nine children with clinical evidence of CLD underwent HRCT. Of these, 39 (28\%) were found to have bronchiectasis (prevalence of 9.5\%). The flow of patients is shown in Flowchart 1. Children in both groups were comparable with respect to sex, mean age at assessment, nutritional status, treatment status, and duration of ART exposure (Table 1).

Where present, bronchiectasis was diffuse in $38 \%$ of children and focal in $36 \%$. Parenchymal disease was seen in $85 \%$ of this cohort. These changes included noncavitating nodules (54\%), treein-bud (31\%), granulomata (23\%), and ground glass (23\%). Areas of hypoattenuation, synonymous with small airways disease, were seen in $97 \%$ of bronchiectatic children. Figure 1 demonstrates some of the HRCT changes seen in our HIV children with bronchiectasis.

Acceptable spirometry data were available in 37 of 39 children in the bronchiectasis group and in all 160 control group children. $\mathrm{FEV}_{1}, \mathrm{FVC}$, and $\mathrm{FEV}_{1} / \mathrm{FVC}$ were significantly reduced by, on average, $2.3,2$, and $0.3 z$-scores, respectively, in children with bronchiectasis when compared to control children (Table 1 and Fig. 2).

The description of one-way analysis of variance (ANOVA) between spirometric values and bronchiectatic children with or without parenchymal disease and control group is shown in Table 2. The magnitude of reduction in $\mathrm{FEV}_{1}, \mathrm{FVC}_{\text {, and }} \mathrm{FEV}_{1} / \mathrm{FVC}$ ratio was larger in children with both bronchiectasis and parenchymal disease.

There was no correlation between $\mathrm{FEV}_{1}$ and age at diagnosis, baseline nutritional and immune status, history/CT evidence of TB, and extent of bronchiectasis on HRCT.

During the $6 \mathrm{MWT}, 41 \%$ of the children with bronchiectasis desaturated as compared to $20 \%$ in the control group (Chi-square $=6.19 ; p=0.01$ ). The distance covered during the walk test was less than 3rd centile against age and gender-matched healthy children in $76 \%$ of children with bronchiectasis as compared to the $57 \%$ in control group, (Chi-square $=3.95 ; p=0.047$ ).

Univariate Cox regression analysis showed that children who were $>5$ years of age (OR 2.52, 95\% Cl $[1.09,5.78], p=0.03)$, growth restricted $(\mathrm{OR} 2.77,95 \% \mathrm{Cl}[1.32,2.83], p=0.01)$, severely 
Flowchart 1: Flow of study participants

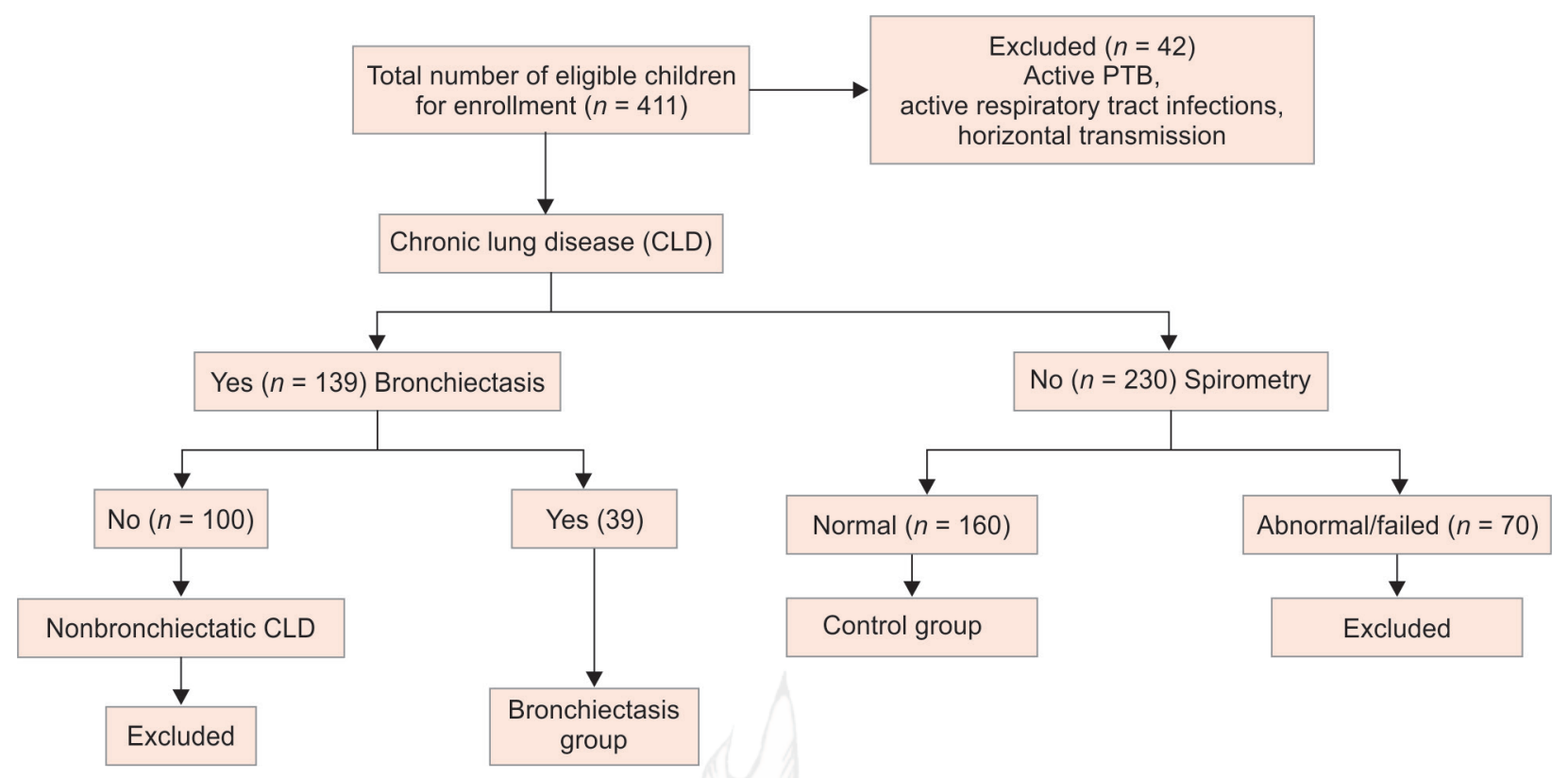

Table 1: Baseline characteristics

\begin{tabular}{|c|c|c|c|c|}
\hline Characteristics & Bronchiectasis group $(n=39)$ & Control group $(n=160)$ & Mean difference $(95 \% \mathrm{Cl})$ & pvalue \\
\hline Male & $23(59 \%)$ & $83(52 \%)$ & & 0.63 \\
\hline Age at HIV diagnosis in years (SD) & $7.0(2.9)$ & $6.5(3.6)$ & $-0.51(-1.75-0.72)$ & 0.41 \\
\hline Age at assessment in years (SD) & $12.1(2.7)$ & $11.4(3.3)$ & $-0.67(-1.80-0.46)$ & 0.19 \\
\hline On ART & $34(87 \%)$ & $120(75 \%)$ & & 0.1 \\
\hline Duration on ART (years) & $4.1(2.2)$ & $4.1(2.5)$ & $0.004(-0.94-0.95)$ & 0.99 \\
\hline On cotrimoxazole prophylaxis & $5(12.8 \%)$ & $40(25 \%)$ & & 0.1 \\
\hline zHeight (SD)* & $-2.2( \pm 1.7)$ & $-1.5( \pm 2.4)$ & $0.73(-0.07-1.52)$ & 0.07 \\
\hline$z$ Weight $\mathrm{f}(\mathrm{SD})^{*}$ & $-2.0( \pm 1.9)$ & $-1.9( \pm 1.5)$ & $0.09(-0.54-0.73)$ & 0.77 \\
\hline zBMI (SD)* & $-1.6( \pm 1.5)$ & $-1.4( \pm 1.8)$ & $0.18(-0.46-0.82)$ & 0.58 \\
\hline$z \mathrm{FEV}_{1}(\mathrm{SD})$ & $-2.6( \pm 0.9)$ & $-0.4( \pm 0.9)$ & $2.24(1.91-2.57)$ & $<0.01$ \\
\hline$z \mathrm{FVC}(\mathrm{SD})$ & $-2.4( \pm 0.8)$ & $-0.5( \pm 0.9)$ & $1.88(1.55-2.21)$ & $<0.01$ \\
\hline$z \mathrm{FEV}_{1} / \mathrm{FVC}(\mathrm{SD})$ & $-0.8( \pm 1.4)$ & $0.4( \pm 0.8)$ & $1.20(0.85-1.55)$ & $<0.01$ \\
\hline
\end{tabular}

ART, antiretroviral therapy; BMI, body mass index; $\mathrm{FEV}_{1}$, forced expiratory volume in 1 second; FVC, forced vital capacity; FEV $/ F V C$, ratio of forced expiratory volume in 1 second to forced vital capacity; HIV, human immunodeficiency virus;

Results are expressed as mean (SD), unless otherwise specified

$z$ Height, $z$ Weight, $z$ BMI are based on Indian growth charts ${ }^{6}$

Spirometry results are adjusted for age, height, and sex based on recently derived Global Lung Function Initiative-2012 coefficients for Indian children ${ }^{12-14}$ *Khadilkar VV, Khadilkar AV, Cole TJ, et al. Cross-sectional growth curves for height, weight and body mass index for affluent Indian children, 2007. Indian Pediatr 2009;46(6):477-489.

immunosuppressed (OR 2.23, 95\% CI [1.08, 4.60], $p=0.03$ ) at HIV diagnosis, and those with preceding recurrent sinopulmonary infections (OR $2.16,95 \% \mathrm{Cl}[1.06,4.40], p=0.03$ ) were at significantly higher risk of having bronchiectasis. Although there was no statistical significance, children with a history of pulmonary TB were 1.98 times (95\% Cl $[0.96,4.06], p=0.06)$ more likely to have bronchiectasis than children without pulmonary TB (Fig. 3).

A multivariable Cox proportional hazards mortality model showed age $>5$ years (OR $3.39,95 \% \mathrm{Cl}[1.30,8.87], p=0.01)$, and preceding recurrent sinopulmonary infections (OR $2.37,95 \% \mathrm{Cl}$ [1.07, 5.24], $p=0.03$ ) at HIV diagnosis as independent risk factors for bronchiectasis (Fig. 3).

\section{Discussion}

The current study is probably the first report from India in HIVinfected children with bronchiectasis in the era of widespread use of ART. The major strength of this study is universal availability of HRCT for the diagnosis of bronchiectasis. In the context of high prevalence of HIV-TB coinfection, this study provides an insight into the role of various risk factors associated with bronchiectasis and pulmonary function in these children.

In our cohort of CLHIV, we found a significant burden of bronchiectasis (9.5\%) associated with poor lung function. Late diagnosis of HIV and recurrent sinopulmonary infections were independently associated with higher odds of having bronchiectasis. 


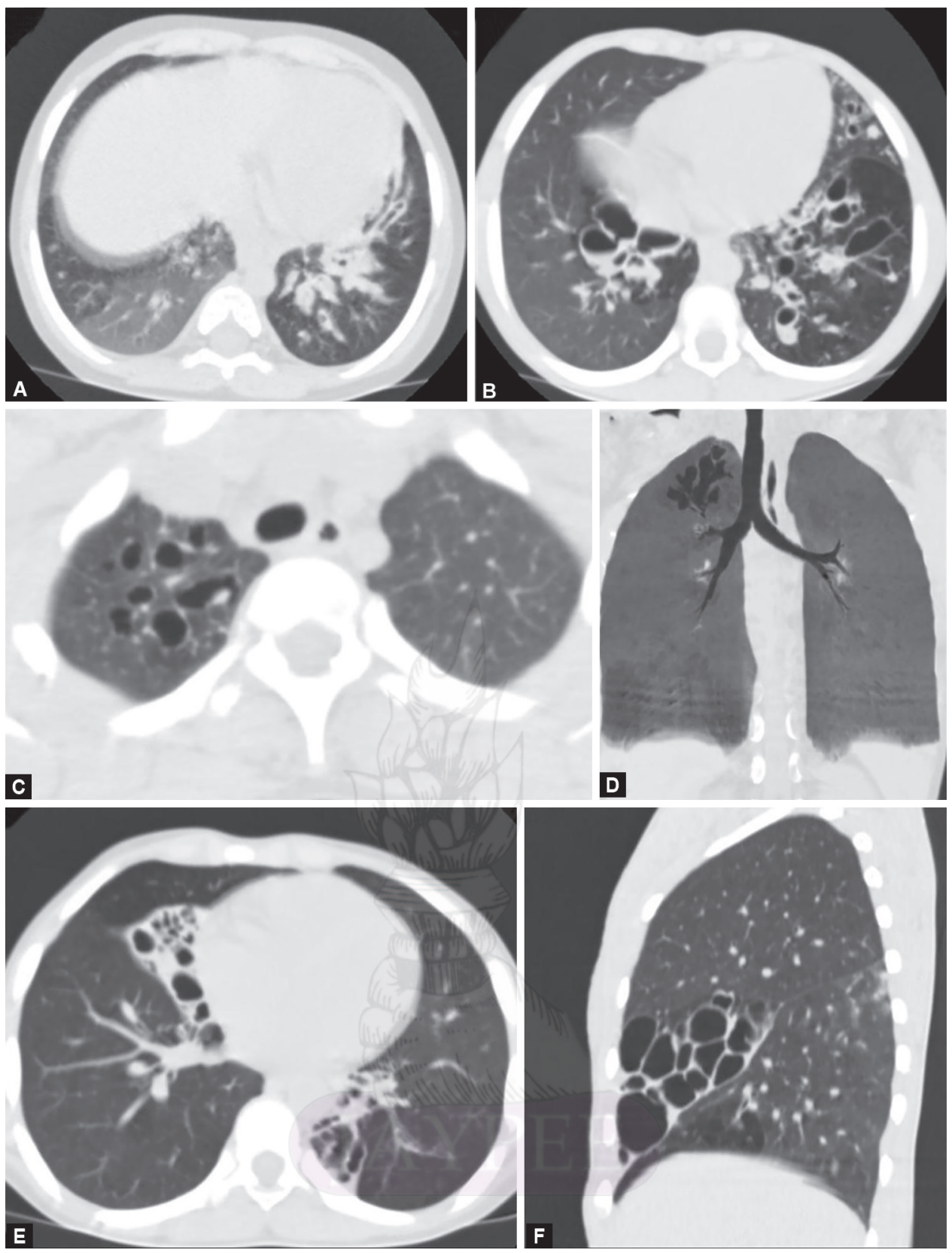

Figs 1A to F: Abnormalities seen on HRCT chest of children with bronchiectasis. (A) Axial CT section through the lung bases of a 6-year-old male with vertically transmitted HIV demonstrating thick walled, dilated, nontapering left lower lobe airways with mucous plugging. Note also the hyperlucency both surrounding the left lower lobe bronchiectasis and in the right lower lobe; (B) Axial CT section demonstrating saccular bronchiectasis with air-fluid levels in both lower lobes and the lingual in a 12-year-old male with vertically transmitted HIV. Note the hyperlucency surrounding the areas of bronchiectasisi; (C and D) Axial section through the lung apices (C) demonstrating marked saccular dilatation of the right upper lobe bronchi in a 13-year-old male with vertically transmitted HIV. The coronal minimum intensity projection (minIP) image (D) shows this saccular bronchiectasis is limited to the apical right upper lobe; (E) Axial CT section demonstrating replacement of the right middle lobe and part of the left lower lobe with saccular and varicose bronchiectasis in a 14-year-old male with vertically transmitted HIV; (F) Sagittal CT section through the right lung. Replacement of the right middle lobe with saccular bronchiectasis in an 18-year-old female with vertically transmitted HIV. There is also ground glass in the apical right lower and hyperlucency in the anterior right lower lobe

Two studies in children with HIV have reported prevalence rates of bronchiectasis ranging from $5.7 \%{ }^{17}$ to $15.8 \% .{ }^{18}$ In both studies, significant proportion of patients were diagnosed without HRCT. The prevalence of bronchiectasis among HIV-infected children with CLD in our study was $28 \%$ (39/139), and the use of HRCT for the diagnosis could be the reason for the higher prevalence noted.
Bronchiectasis in children with HIV has been associated with recurrent pneumonia, lymphoid interstitial pneumonitis (LIP), and severe immunosuppression. ${ }^{17,18}$

The severity of bronchiectasis in our children varied from focal unilobar involvement to extensive cicatrizing bilateral involvement. However, there was no correlation between severity (defined as 

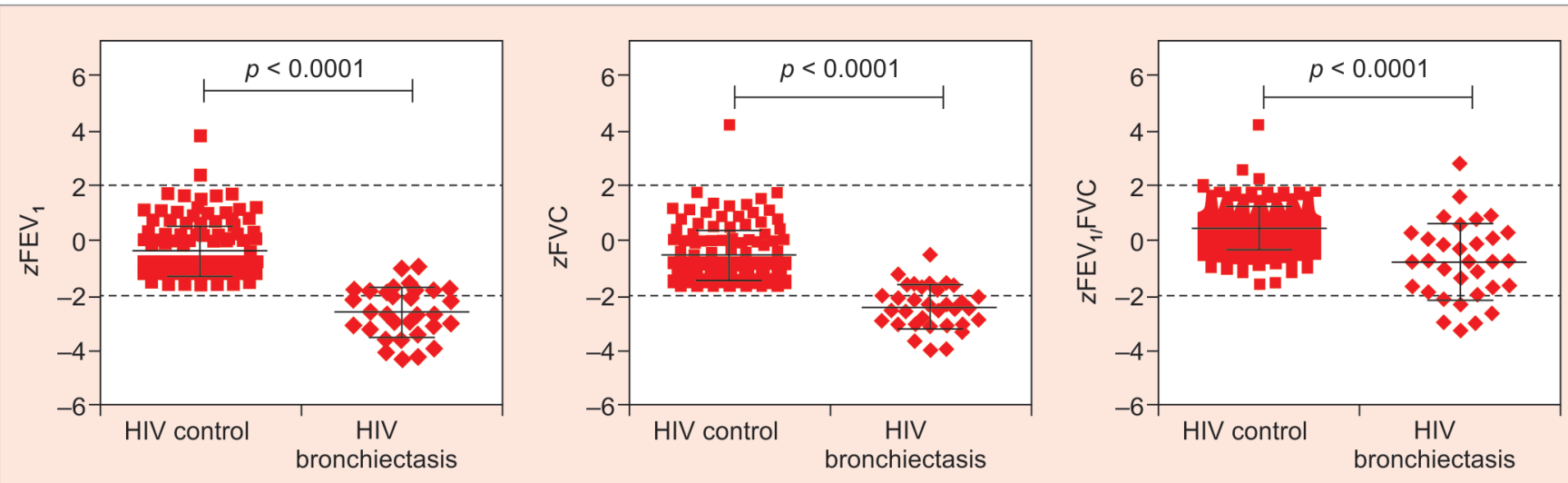

Fig. 2: Spirometry data in children with HIV according to Global Lung Function Initiative-2012 equations. Solid black lines indicate mean and SD. Dashed lines depict $\pm 2 z$-scores, within which $95 \%$ of well-nourished Indian children would fall ${ }^{13,14}$

Table 2: One way ANOVA between spirometry and associated parenchymal disease

\begin{tabular}{|c|c|c|c|c|c|}
\hline & HRCT characteristics & Mean & Standard deviation & $95 \%$ Cl for mean & $p$ value \\
\hline \multirow[t]{3}{*}{$z$-score FEV1 } & $\begin{array}{l}\text { Bronchiectasis } \\
\text { without parenchymal } \\
\text { disease }\end{array}$ & -1.53 & 0.51 & -2.17 to -0.90 & $<0.01$ \\
\hline & $\begin{array}{l}\text { Bronchiectasis with } \\
\text { parenchymal disease }\end{array}$ & -2.80 & 0.81 & -3.11 to -2.48 & \\
\hline & Control group & -0.37 & 0.87 & -0.50 to -0.23 & \\
\hline \multirow[t]{3}{*}{ z-score FVC } & $\begin{array}{l}\text { Bronchiectasis } \\
\text { without parenchymal } \\
\text { disease }\end{array}$ & -1.53 & 0.71 & -2.41 to -0.66 & $<0.01$ \\
\hline & $\begin{array}{l}\text { Bronchiectasis with } \\
\text { parenchymal disease }\end{array}$ & -2.59 & 0.71 & -2.87 to -2.32 & \\
\hline & Control group & -0.55 & 0.88 & -0.69 to -0.41 & \\
\hline \multirow[t]{3}{*}{$z$-score FEV1/FVC } & $\begin{array}{l}\text { Bronchiectasis } \\
\text { without parenchymal } \\
\text { disease }\end{array}$ & -0.09 & 1.10 & -1.45 to -1.28 & $<0.01$ \\
\hline & $\begin{array}{l}\text { Bronchiectasis with } \\
\text { parenchymal disease }\end{array}$ & -0.93 & 1.45 & -1.50 to -0.36 & \\
\hline & Control group & 0.41 & 0.78 & $0.28-0.53$ & \\
\hline
\end{tabular}

extent of involvement) of bronchiectasis with age at diagnosis, baseline nutritional, or immune status. Parenchymal involvements such as noncavitatory nodules, tree-in-bud, ground glass opacities, and mosaic attenuation were seen in a majority of these children. A third of our children with bronchiectasis had features suggestive of nontuberculous mycobacterial infection and/or constrictive bronchiolitis. HRCT signs of nontuberculous mycobacterial infection include bronchiectasis, nodules, tree-in-bud, patchy consolidation, and cavities, often affecting the upper lobes and superior segments of lower lobes in the classic subtype and middle lobe/lingula in the non-classic subtype. ${ }^{19}$ As our cohort had stable HIV disease and were not acutely unwell, nontuberculous mycobacterial infection is unlikely. HRCT findings in constrictive bronchiolitis include both central and peripheral bronchiectasis, bronchial wall thickening, centrilobular nodules, and tree-in-bud appearance. ${ }^{20}$ Constrictive bronchiolitis is associated with several insults causing lung injury, including collagen vascular diseases, inhalation of allergens or toxins, and infection with pathogens such as adenovirus, mycoplasma, respiratory syncytial virus, influenza, or HIV itself. In an African cohort of adolescents with vertically acquired HIV, constrictive bronchiolitis was the most common cause of CLD including bronchiectasis. ${ }^{8}$ This led the authors to speculate that the frequent respiratory tract infections that occur in untreated HIV-infected children result in cumulative inflammatory damage causing small airway disease and development of bronchiectasis. $^{8}$

Functionally, FEV, FVC, and their ratio were significantly lower in children with bronchiectasis than the children without CLD. Weber et al. found that median $\mathrm{FEV}_{1}$ was $60 \%$ of the predicted in their cohort of HIV-infected children with CLD including bronchiectasis. ${ }^{21}$ Ferrand et al. showed abnormal spirometry ( $\mathrm{FEV}_{1}<80 \%$ of predicted) in $45 \%$ of their CLD children with HIV. ${ }^{8}$ This lower prevalence of abnormal spirometry in their study could be due to inclusion of nonbronchiectatic CLD children and also older age of children in their cohort. Many studies have shown negative correlation between severity of bronchiectasis and pulmonary function in adults but not in HIV-infected children, ${ }^{18}$ which was also replicated in our study. Nevertheless, in children with bronchiectasis 


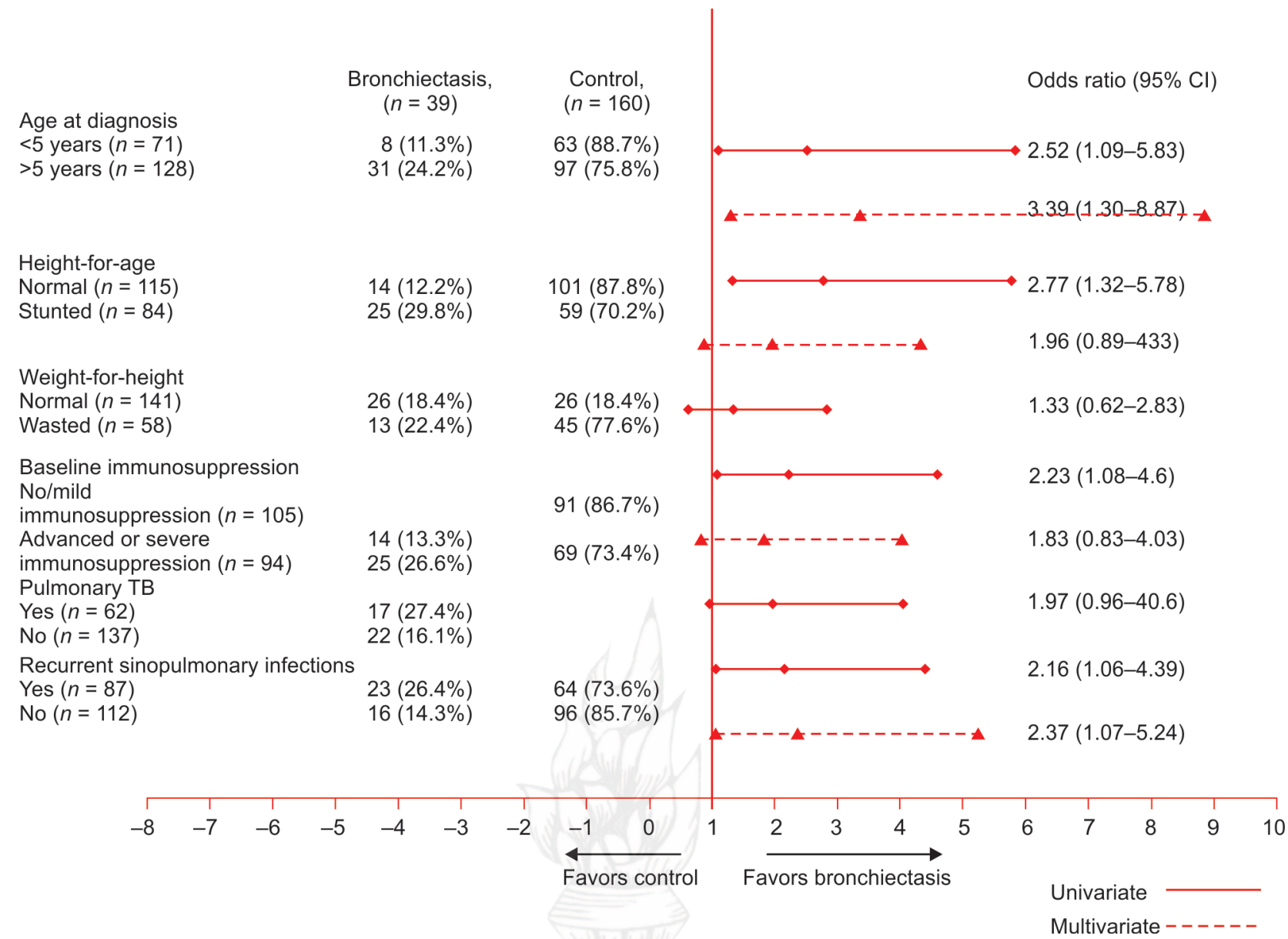

Fig. 3: Forest plot showing odds ratios $(95 \% \mathrm{Cl})$ for various risk factors associated with bronchiectasis in children with vertically transmitted HIV infection

and parenchymal disease, the magnitude of reduction in $\mathrm{FEV}_{1}, \mathrm{FVC}$, and $\mathrm{FEV}_{1} / \mathrm{FVC}$ ratio was larger.

The incidence of bronchiectasis was significantly higher when HIV was diagnosed after the age of 5 years. Masekela et al. showed that mean age of diagnosis of HIV was 6.9 years in their cohort of 35 bronchiectatic children. ${ }^{22}$ As the age above 5 years at HIV diagnosis is an independent risk factor, the direct role of HIV in the development of bronchiectasis needs to be investigated. Late HIV diagnosis and consequent delay in ART initiation increases the vulnerability to opportunistic infections including recurrent sinopulmonary infections which may result in bronchiectasis.

It was found that significantly higher number of growth restricted children had bronchiectasis than children with normal height. The impact of nutrition on lung morbidity is well-described in cystic fibrosis, where children with low BMIs suffer higher morbidity from lung disease. ${ }^{23}$ Multiple factors are responsible for the short stature in children with HIV infection including increased metabolic demand due to CLD, HIV infection, and recurrent opportunistic infections or poor socioeconomic status or HIV-associated wasting syndrome. Hence, it is difficult to establish the role of these individual factors as cause or effect of bronchiectasis. In the current study, bronchiectasis was seen more frequently in severely immunosuppressed children than in no or mildly immunosuppressed children at baseline. This prevalence of bronchiectasis among children with varying severity of immunosuppression shown in our study is in contrast to the estimation of level of immunosuppression among children with bronchiectasis reported in the literature. $17,18,24,25$

Contrary to expectations, pulmonary TB (as determined by history and case note review) was not significantly associated with bronchiectasis. The diagnosis of bronchiectasis in the context of high burden of pulmonary TB is challenging. The prevalence of TB in HIV-infected children varies between $30 \%$ and $60 \%$ in India., ${ }^{3,4}$ The difficulties of diagnosing TB in HIV-infected children are well-documented, and in a high TB burden country like India, there may be overreliance on radiological diagnosis. This has led to overdiagnosis of TB due to radiological similarities between TB and CLD which may result in bronchiectasis. Many children in our study received anti-TB treatment more than once, as diagnosis of pediatric TB depends heavily on chest X-ray interpretations.

Recurrent sinopulmonary infections preceding HIV diagnosis are significantly and independently associated with bronchiectasis. Shiekh et al. showed higher incidence of bronchiectasis in children with AIDS pneumopathy with recurrent or unresolved pneumonia. ${ }^{18}$ Berman et al. showed very high incidence of recurrent pneumonia preceding the diagnosis of bronchiectasis. ${ }^{17}$ Unlike in children without HIV infection, management of sinopulmonary infections in HIV-infected children may require a different approach such as specific antimicrobials for longer duration, as inadequately treated sinopulmonary infections could herald a vicious cycle of 
inflammation leading to bronchial wall destruction and irreversible dilatation which is the hallmark of bronchiectasis. ${ }^{26}$ It is wellestablished fact that cotrimoxazole preventive therapy (CPT) is one of the strategies to prevent serious recurrent bacterial infections in children. Prompt implementation of current recommendations of early diagnosis of HIV infection and universal initiation of ART and CPT to all children below 5 years can potentially prevent bronchiectasis. $^{27}$

Few pediatric studies show an association between LIP and bronchiectasis. However, the role of LIP as a risk factor for bronchiectasis could not be evaluated in our study due to nonavailability of diagnostic facilities. As viral load monitoring is routinely not available in the national program, the role of viral load in the development of bronchiectasis could not be established. Further prospective studies are needed to evaluate the role of these risk factors in the development of bronchiectasis in HIV-infected children. Longitudinal follow-up of these children with spirometry to assess the progression of bronchiectasis and impact of ART should be the focus of future research.

To conclude, bronchiectasis is widely prevalent in HIV-infected children with the severity varying from focal to diffuse disease. Lung function in these children is significantly impaired. Age of the children above 5 years at HIV diagnosis and preceding recurrent sinopulmonary infections are associated risk factors for bronchiectasis. Further studies should focus on exploring measures to prevent bronchiectasis in children with HIV.

\section{References}

1. Ferrand RA, Luethy $R$, Bwakura $F$, et al. HIV infection presenting in older children and adolescents: a case series from Harare, Zimbabwe. Clin Infect Dis 2007;44(6):874-878. DOI: 10.1086/511878.

2. National AIDS Control Organisation (NACO). Annual Report 2016. Available from: http://naco.gov.in/sites/default/files/Annual\%20 Report\%202015-16_NACO.pdf (accessed on January 10, 2017).

3. Rajasekaran S, Jeyaseelan L, Raja K, et al. Demographic \& clinical profile of HIV infected children accessing care at Tambaram, Chennai, India. Indian J Med Res 2009;129(1):42-49.

4. Sanjeeva GN, Sukanya V, Shivananda GM. Clinical profile, treatment response, and outcome of HIV-TB co-infected children. Pediatr Infect Dis J 2013;5:3-8. DOI: 10.1016/j.pid.2012.12.014.

5. Callahan CW, Redding GJ. Bronchiectasis in children: orphan disease or persistent problem? Pediatr Pulmonol 2002;33(6):492-496. DOI: 10.1002/ppul.10104.

6. Khadilkar VV, Khadilkar AV, Cole TJ, et al. Crosssectional growth curves for height, weight and body mass index for affluent Indian children, 2007. Indian Pediatr 2009;46(6):477-489.

7. Central Tuberculosis Division. National guideline for partnership, Revised National Tuberculosis Control Programme. 2014. Directorate General of Health Services, Ministry of Health and Family Welfare, Government of India. Available from: http://tbcindia.nic.in/ WriteReadData/l892s/9659721466Guideline\%20for\%20Partnership. pdf (accessed June 9, 2016).

8. Ferrand RA, Desai SR, Hopkins C, et al. Chronic lung disease in adolescents with delayed diagnosis of vertically acquired HIV infection. Clin Infect Dis 2012;55(1):145-152. DOI: 10.1093/cid/cis271.
9. Wormanns D, Hamer OW. [Glossary of terms for thoracic ImagingGerman version of the fleischner Society recommendations]. [Article in German]. Rofo Fortschr Geb Rontgenstr Neuen Bildgeb Verfahr 2015;187(8):638-661. DOI: 10.1055/s-0035-1553216.

10. Pasteur MC, Bilton D, Hill AT. British thoracic society bronchiectasis non-CF guideline group. British thoracic society guideline for non-CF bronchiectasis. Thorax 2010;65:1-58. DOI: 10.1136/thx.2010.136119.

11. Pitcher RD, Lombard CJ, Cotton MF, et al. Chest radiographic abnormalities in HIV-infected African children: a longitudinal study. Thorax 2015;70(9):840-846. DOI: 10.1136/thoraxjnl-2014-206105.

12. Kirkby J, Welsh L, Lum S, et al. The EPICure study: comparison of pediatric spirometry in community and laboratory settings. Pediatr Pulmonol 2008;43(12):1233-1241. DOI: 10.1002/ppul.20950.

13. Quanjer PH, Stanojevic S, Cole TJ, et al. Multi-ethnic reference values for spirometry for the 3-95-yr age range: the global lung function 2012 equations. Eur Respir J 2012;40(6):1324-1343. DOI: 10.1183/09031936.00080312.

14. Kirkby J, Lum S, Stocks J, et al. Adaptation of the GLI- 2012 spirometry reference equations for use in Indian children. European Respiratory Society 2014;44:191.

15. ATS Statement: guidelines for the six-minute walk test. Am J Respir Crit Care Med 2016;193(10):1185. DOI: 10.1164/rccm.19310erratum.

16. Ulrich S, Hildenbrand FF, Treder U, et al. Reference values for the 6-minute walk test in healthy children and adolescents in Switzerland. BMC Pulm Med 2013;13:49. DOI: 10.1186/1471-2466-13-49.

17. Berman DM, Mafut D, Djokic B, et al. Risk factors for the development of bronchiectasis in HIV-infected children. Pediatr Pulmonol 2007;42(10):871-875. DOI: 10.1002/ppul.20668.

18. Sheikh S, Madiraju K, Steiner P. Bronchiectasis in pediatric AIDS. Chest 1997;112(5):1202-1207. DOI: 10.1378/chest.112.5.1202.

19. Perera PL, Screaton NJ. Radiological features of bronchiectasis. Eur Respir Mon 2011;52:44-67. Available from: http://www. sppneumologia.pt/uploads/files/spp/PDF79.pdf (accessed on January 10, 2017). DOI: 10.1183/1025448x.10003510.

20. Rossi SE, Franquet T, Volpacchio M, et al. Tree-in-bud pattern at thin-section CT of the lungs: radiologic-pathologic overview. Radiographics 2005;25(3):789-801. DOI: 10.1148/rg.253045115.

21. Weber HC, Gie RP, Wills K, et al. Clinical features and lung function in HIV-infected children with chronic lung disease. S Afr J Child Health 2015;9(3):72-75. DOI: 10.7196/SAJCH.7940.

22. Masekela R, Anderson R, Moodley T, et al. HIV-related bronchiectasis in children: an emerging spectre in high tuberculosis burden areas. Int J Tuberc Lung Dis 2012;16(1):114-119. DOI: 10.5588/ijtld.11.0244.

23. Chang AB, Grimwood K, Maguire G, et al. Management of bronchiectasis and chronic suppurative lung disease in indigenous children and adults from rural and remote Australian communities. Med J Aust 2008;189(7):386-393. DOI: 10.5694/j.1326-5377.2008. tb02085.x.

24. McGuinness G, Naidich DP, Garay S, et al. AIDS associated bronchiectasis: CT features. J Comput Assist Tomogr 1993;17(2): 260-266. DOI: 10.1097/00004728-199303000-00015.

25. Holmes AH, Trotman-Dickenson B, Edwards A, et al. Bronchiectasis in HIV disease. Q J Med 1992;85(307-308):875-882.

26. Cole PJ. Inflammation: a two-edged sword-the model of bronchiectasis. Eur J Respir Dis Suppl 1986;147:6-15.

27. National AIDS Control Organisation (NACO). Pediatric Antiretroviral Therapy (ART) Guidelines, 2013. Available from: http://naco.gov.in/ sites/default/files/Pediatric_14-03-2014.pdf (accessed June 9, 2016). 